\title{
INTERMITTENT IRRIGATION ENHANCES MORPHOLOGICAL AND PHYSIOLOGICAL EFFICIENCY OF RICE PLANTS
}

\author{
ABHA MISHRA \\ Asian Centre of Innovation for Sustainable Agriculture Intensification (ACISAI), \\ Asian Institute of Technology, Klong Luang, Pathumthani
}

MISHRA, A.: Intermittent irrigation enhances morphological and physiological efficiency of rice plants. Agriculture (Pol'nohospodárstvo), vol. 58,2012 , no. 4 , pp. 121-130.

\begin{abstract}
The response of rice roots and shoots and their causal relationships affecting yield under varying soil water condition are important related subjects of research. To understand the mechanism of response, studies were conducted using four water treatments: a) intermittent flooding through the vegetative stage (IF-V); b) intermittent flooding extended into the reproductive stage (IF-R); c) no standing water (NSW), maintaining soil at field capacity; and d) continuous flooding (CF) condition at the Asian Institute of Technology in Thailand. It was observed that the senescence of lower leaf and flag leaf was delayed under IF-V compared to CF water condition. This delay was associated with higher root oxidizing activity (ROA) rate $(50 \%$ higher than $\mathrm{CF})$, higher root length density (RLD) (52\% higher than CF), higher biomass production (14\% higher
\end{abstract}

than $\mathrm{CF}$ ) along with higher grain yield (25\% higher than $\mathrm{CF}$ ). The plants grown under NSW conditions had better growth at later growth stage and better yield performance compared to IF-R because of higher nitrogen availability and higher uptake rate under NSW water conditions (73\% higher $\mathrm{N}$ uptake). However, under CF water condition the nitrogen availability was not a limiting factor but due to decreased root activity rate the dry matter production and grain yield significantly reduced compared to IF-V water condition.

The results suggested that ROA and RLD are linked to shoot response and to dry matter production. A better understanding of the underlying mechanisms should assist in achieving improvements in crop productivity through improved crop management practices in water-limiting environment.

Key words: water saving irrigation, root senescence, root oxidizing activity rate, root length density, chlorophyll content

Several research groups have shown that when paddy soils dry, water deficits first appear near the surface and then progress to the deeper layers; increased depth of rooting is common under drying soil conditions (Proffitt et al. 1985; Newell \& Wilhelm 1987). Gallardo et al. (1994) found that drought increased the root growth in the lower soil layers in a pot study where only the upper third of the soil was allowed to dry. It is well known that water and $\mathrm{N}$ supply, either availability or form of $\mathrm{N}$, often interact with each other and are important factors for higher rice yield and root development (Skinner et al. 1998).

The status, form and availability of soil $\mathrm{N}$ in the rhizosphere depends on the water regime employed, i.e., on the soil's aerobic/anaerobic environment, which in turn influences roots' oxidation ability and proliferation (Mishra et al. 2006). A higher rate of root activity contributes to a higher photosynthetic rate by supplying a sufficient amount of nutrients to the shoots, thus achieving high productivity (Osaki et al. 1997). Although these morphological and physiological responses are known to be prompted by agronomic management practices, there was little appreciation of how to adapt irrigated rice production to changing climate circumstances. Renewed interest in root research has thus far mostly taken conventional pathways, i.e., breeding approaches are being invoked to address the effects of climate variability (Gewin 2010). However, this emerging variability, especially changing wateravailability scenarios, should promote some reorienta- 
tion in our research approach, i.e., taking into consideration the effects of management practices that could optimize water use without compromising the yield.

In this context, the term 'water-saving irrigation' has been introduced to describe producing more rice with less water. This involves: (i) reducing the depth of ponded water, (ii) keeping the soil just saturated, not continuously flooded, or (iii) employing intermittent irrigation or alternate wetting and drying, i.e., allowing the soil to dry out to a certain extent before re-applying irrigation water.

Some previous reports on the effects of cessation of flooding through intermittent irrigation have suggested that under unsaturated soil moisture conditions, there is a significant decrease in dry matter production and grain yield for rice (McCauley 1990; Mishra et al. 1997). It is suggested that this could be due to a rapid rate of loss of nitrogen facilitated by nitrification and denitrification (Sah \& Mikkelson 1983). However, others have reported higher yields associated with intermittent irrigation during the vegetative stage when accompanied by other agronomic management practices, such as young, single seedling transplants with optimum spacing (Ceesay et al. 2006; Sato \& Uphoff 2007), and even under post-anthesis water-deficit conditions when organic matter has been applied to the soil (Yang et al. 2003).

With reference to the above findings, it can be suggested that when rice plants are continuously flooded from the start, from the time of transplanting, their roots will degenerate (Kar et al. 1974), so that when the crop is subjected to water stress after flowering, there is a definite reduction in crop yield. On the other hand, if there is AWD or minimum water application from the start, and rice plant roots grow larger and deeper, such plants can tolerate subsequent water stresses (in the upper soil horizon). This needs to be confirmed through research.

Such reports on the effects of continuous flooding and intermittent irrigation and/or non-flooded water regimes for rice production leave some important questions unanswered, since they did not assess how rice plants' roots and shoots will respond to different soilmoisture conditions. Also, whether these responses, if they occur, will lead to greater dry matter production or to less is not known. This is a research area warranting investigation.

For the improvement of root systems and subsequent yields through alterations in water management, it is critical to understand the relative importance of water regimes on the soil's nitrogen status and availability, on root development, and on subsequent plant growth. This experiment studied the effect of different water regimes on the root and shoot growth of rice. The paper examines these relationships to get a better understanding of the effects that varying water regime can have on the soil's available nitrogen status (supply) and forms, and on the rice plant's root and shoot development, looking for any causal relationships that could affect the crop yield-contributing parameters.

$\mathrm{T}$ a $\mathrm{b} 1 \mathrm{e} \quad 1$

Soil characteristics of experimental soil $(0-10 \mathrm{~cm})$ used for pot experiment

\begin{tabular}{|c|c|}
\hline Soil series & Ongkharak \\
\hline Texture & Clay \\
Sand [\%] & 10.20 \\
Silt [\%] & 23.20 \\
Clay [\%] & 66.20 \\
pH (1:1) & 5.00 \\
Organic C [\%] & 1.38 \\
Total N [\%] & 0.14 \\
Available P [ppm] & 11.00 \\
Available K [ppm] & 212.00 \\
CEC [cmol/kg] & 22.60 \\
\hline
\end{tabular}




\section{MATERIAL AND METHODS}

\section{a) Experimental Set-up}

The experiment was conducted from 2005 to 2006 in an open-sided greenhouse with plastic roof (light transmissivity 93\%) at the Asian Institute of Technology, Bangkok, Thailand at $14^{\circ} 04^{\prime} \mathrm{N}$ latitude and $100^{\circ}$ $37^{\prime}$ E longitude with $2.27 \mathrm{~m}$ altitude. Average temperature range was $30-35^{\circ} \mathrm{C}$, and relative humidity $(\mathrm{RH})$ was $75-85 \%$.

Black clay soil was collected from the Rice Research Station of Asian Institute of Technology, Thailand. The soil samples were taken from the $0-10 \mathrm{~cm}$ layer. Table 1 shows some selected properties of this soil. The sample was analyzed for soil $\mathrm{pH}$, cation exchange capacity (CEC), Bray P, total N, K (Kjeldahl method), P (Bray II), and organic C (Automatic Nitrogen and Carbon Analyser-Mass Spectrometer).

After air drying, the soil samples were crushed, and crop residues were removed by hand. In each plastic pot $(60 \mathrm{~cm}$ high with diameters $50 \mathrm{~cm}$ at the top and $40 \mathrm{~cm}$ at the bottom) was placed $65 \mathrm{~kg}$ of soil. All pots were flooded by the addition of distilled water to a depth of 3-4 $\mathrm{cm}$ for a week before transplanting and were dressed with $138 \mathrm{mg} \mathrm{N}$ and $12.3 \mathrm{mg} \mathrm{P}$ per $\mathrm{kg}$ of soil applied in NPK fertilizer - 16:16:0 as basal application, and urea $(46: 0: 0)$ at 15 and 45 days after transplanting (DAT). Single 15-day-old seedlings (variety Pathumthani; maturity period $=120$ days; nonphotosensitive) with two fully-expanded leaves grown in a dry seedbed were transplanted within 2 hours of uprooting from the nursery seedbed with a sowing depth of $1.5 \mathrm{~cm}$.

\section{b) Water supplies}

Water treatment was started 7 days after transplanting, when transplanting shock had disappeared (Figure 1). The following four water treatments were applied:

(i) Continuous flooding (CF) $-5 \mathrm{~cm}$ depth of ponded water was maintained until maturity.

(ii) Shorter intermittent flooding (IF-V) $-5 \mathrm{~cm}$ depth of water was maintained every day for 12 days, then drained for three days, and again re-flooded with the same depth of ponded water. (Water was drained from the bottom of the pot by a drainage hole and was collected in a container and stored in a refrigerator during drying, being returned to the pots when re-flooding was done.) A 3-day drying period was provided at 19, 34 and 50 DAT followed by flooded water treatment until maturity.

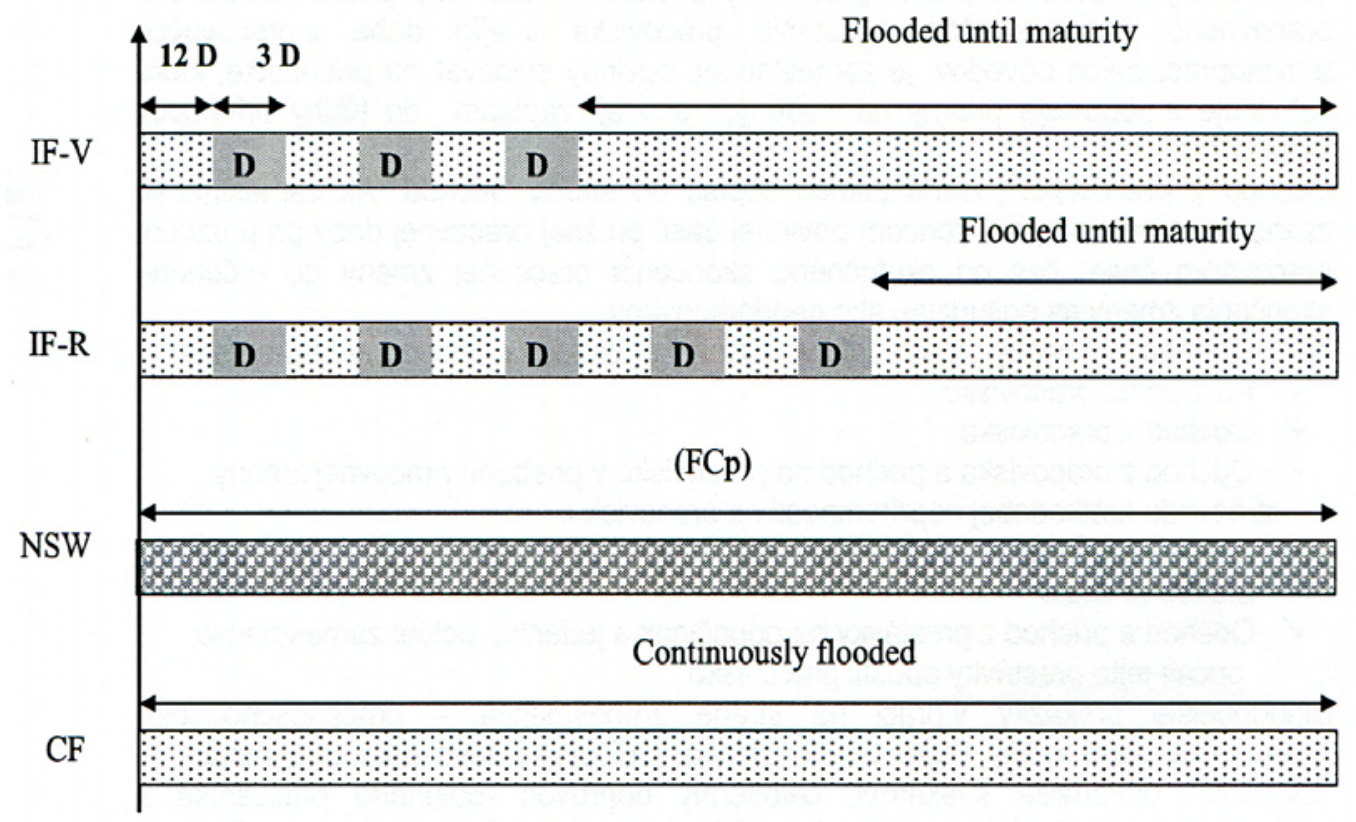

Figure 1. Irrigation schedule in IF-V, IF-R, NSW and CF water regimes $(\mathrm{FCp}=$ at field capacity, D $=$ drainage, $d=$ days $)$ 
(iii) Longer intermittent flooding (IF-R) - similar procedures like IF-V were followed five times, at 19, 34, 50, 66 and 82 DAT, followed by flooded water until maturity.

(iv) No standing water (NSW) - pots were maintained with no standing water at the soil surface but with water concentrations kept at field capacity (FCp) in the rooting zone. To maintain the soil at field capacity $(21 \% \mathrm{v} / \mathrm{v}$ of soil) in the rooting zone, a moisture meter (WET Sensor, 4.1) was used, calibrated for clay soil with a rooting depth of $235 \mathrm{~mm}$; water was added at intervals of 24 hours every day to maintain the status quo by checking moisture percentage every day.

Commencing from one week before transplanting, soil $\mathrm{pH}$ was measured weekly by using a portable $\mathrm{pH}$ meter with a glass-calomel electrode inserted into the soil to a 5-10 cm depth.

\section{c) Plant parameters measurement}

Parameters affecting the yield of rice were studied by observing the number of panicles/plant, panicle length, filled grains/panicle, and plant biomass. The grain-filling rate was calculated by using the following equation:

$$
W=\mathrm{A} /\left(1+B \mathrm{e}^{-k t}\right)^{1 / N} \text { and } \mathrm{G}=A K B \mathrm{e}^{-k t} /\left(1+B \mathrm{e}^{-k t}\right)^{1 / N}
$$

where:

$W=$ grain weight $[\mathrm{mg}]$,

$A=$ final grain weight,

$t=$ time after anthesis [d], and

$B, k$, and $N$ are the coefficients determined by regression. The active grain-filling period is defined as the days when $W$ went from $5 \%(t 1)$ to $95 \%(t 2)$ of A. An average grain-filling rate during this period was therefore calculated from $t 1$ to $t 2$.

Physiological parameters were studied by observing the number of days to flowering (from the date of sowing), days to physiological maturity (from the date of sowing), and active grain-filling period. The chlorophyll content of the flag leaf and third leaf were recorded from the flowering to physiological-maturity stages at intervals of 7 days using a chlorophyll meter (SPAD 502; Minolta Corp; Tokyo). Prior to this, the SPAD 502 was calibrated by using spectrophotometric assays in order to determine the exponential equation to directly convert its output to leaf chlorophyll concentration (Markwell et al. 1995). These data were col- lected from undisturbed pots which had not been used for doing root study and nitrogen estimation.

For root study, soil samples were collected from pots four pots from each treatment combination at flowering (72 DAT) and from another four pots at 20 days after flowering (DAF), i.e., at 92 DAT, from the upper $(15-20 \mathrm{~cm})$ and subsoil $(35-40 \mathrm{~cm})$ layers for root length, root weight, and root-oxidizing activity. (Collected root samples were washed and dried in an oven at $65^{\circ} \mathrm{C}$ ).

\section{d) Root-oxidizing activity measurement}

The root activity rate was measured by assaying the oxidation of alpha-naphthylamine (Zhang et al. 1994). One gram of fresh root was immersed in $100 \mathrm{ml}$ of 20 ppm alpha-naphthylamine test solution for $10 \mathrm{~min}$ utes to exclude initial rapid absorption of alpha-naphthylamine by roots. The intact roots were then transferred to another $100 \mathrm{ml}$ of $20 \mathrm{ppm}$ of alpha-naphthylamine tests solution maintained at $25 \pm 1{ }^{\circ} \mathrm{C}$ and were incubated up to four hours. After 2 and 4 hours of incubation, $2 \mathrm{ml}$ of alpha-napthylamine sample solution was pipetted out and reacted with $10 \mathrm{ml}$ of $0.1 \%$ sulfanilic acid (in 3\% acetic acid), and then with $2 \mathrm{ml}$ of $50 \mathrm{ppm} \mathrm{NaNO}_{2}$. After that, the solution was diluted to $25 \mathrm{ml}$ with distilled water. The absorbance of the coloured solution was determined at $530 \mathrm{~nm}$ using spectrophotometer.

\section{e) Soil nitrogen estimation}

Available nitrogen was measured at flowering and at 20 DAF by using soil from the same pots used for root study. Cores of soil were drawn from the entire depth of soil at corresponding dates (72 DAT at flowering and 92 DAT at 20 DAF) when pots were maintained with $5 \mathrm{~cm}$ water depth from the soil surface in CF, IF-V and IF-R and at field capacity in NSW water regimes. Fresh soil drawn from the pots was extracted using $2 \mathrm{~N} \mathrm{KCl}$ solution followed by distillation using $\mathrm{MgO}$ for ammonium $\left(\mathrm{NH}_{4}^{+}\right)$and Devarda alloy for nitrate $\left(\mathrm{NO}_{3}\right)$, and titration with standard sulphuric acid. Values are expressed on a dry soil basis.

\section{f) Experimental design and analyses}

The experiment was set up with completely randomized block design with twelve replications of each treatment combination. Since destructive samplings were done for root parameters and for $\mathrm{N}$ estimation at flowering and $20 \mathrm{DAF}$, there were four replications; 
four were used at flowering, four at $20 \mathrm{DAF}$, and four at harvesting for data analysis. Data were analyzed by using Sigma stat (3.1). One-way ANOVA was performed followed by mean separation by Tukey's HSD test. A significance level of $P<0.05$ was used for all analyses.

\section{RESULTS}

Under continuously flooded conditions, soil $\mathrm{pH}$ varied from 6.1 to 6.5 throughout the crop growth period, whereas under NSW water regimes, soil $\mathrm{pH}$ was around 4.75. In intermittent irrigation, soil $\mathrm{pH}$ varied according to the soil flooding and drying phase (Figure 2).

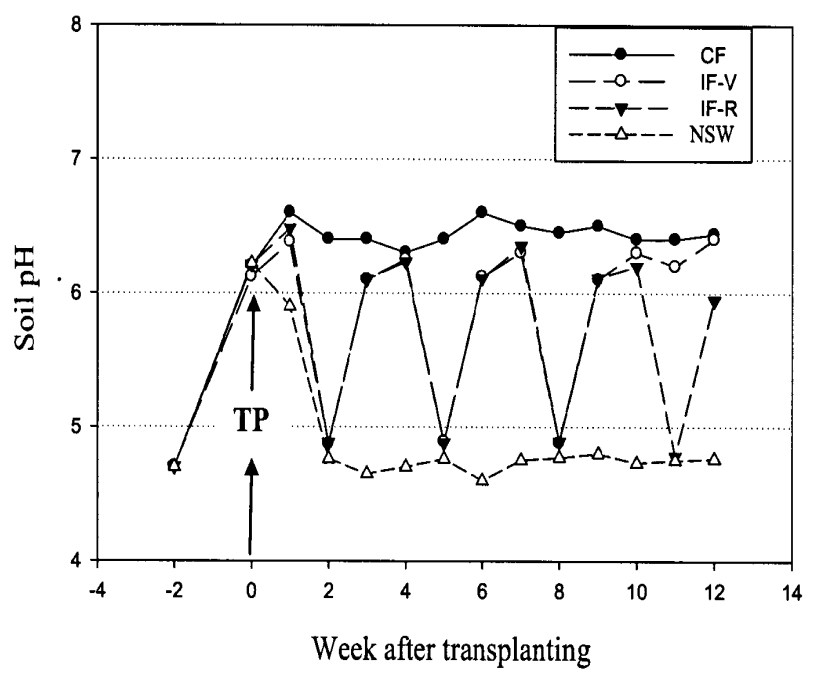

Figure 2. Changes in soil $\mathrm{pH}$ at soil depth of 5-10 $\mathrm{cm}$ under $\mathrm{CF}$ (continuously flooded), IF-V (intermittent draining for three times), IF-R (intermittent draining for five times) and NSW (no standing water on the soil surface) water regimes

\section{a) Rice growth and yield-contributing parameters}

Plant height was significantly higher under continuously flooded (CF) conditions as compared to the intermittent draining until vegetative stage (IF-V) and intermittent draining until reproductive stage (IF-R). Under the NSW condition, plant height was shortest due to less inter-node elongation along with a decrease in length of the neck. Tiller numbers did not vary significantly among CF, IF-V and IF-R at vegetative stage compared to NSW, but productive tillers were significantly lowered in CF compared to IF-V and IF-R. In the NSW treatment, tiller degeneration was not seen, but the rate of tiller growth was slower compared to the IF-V, IF-R and the CF (Table 2).

The vegetative growth stage was slightly shorter in the IF-V and IF-R compared to the CF treatment. Plants grown under NSW water regimes had the longest vegetative growth stage. Panicles were longer in the IF-V and CF treatments with a greater number of spikelets/panicle compared to the IF-R and NSW treatments. However, with CF, only $80 \%$ of spikelets were filled (Table 2). Spikelet sterility was lowest in NSW followed by IF-V treatment. Single grain weight was higher in the IF-V and NSW compared to the IF-R and $\mathrm{CF}$ treatments, although the grain-filling rate was higher in the NSW and IF-R treatments compared to IF-V and CF treatments (Table 2).

The highest biomass production was recorded in the IF-V treatments followed by CF, NSW and IF-R. Similar trends were recorded for the grain weight (Table 5).

\section{b) Root growth and nutrient uptake}

At flowering, there was no difference recorded in the root distribution in the upper soil depth in the IF-V and CF treatments and, in these treatments, most of the roots were observed to be distributed in the upper soil layer. In contrast, fewer roots were observed at lower soil depth in the CF compared to the IF-V. A slight decrease in root distribution was observed in the IF-R at both soil depths, whereas in the NSW treatments, fewer roots were observed only at an upper soil depth compared to the IF-V, IF-R and CF (Table 3).

The distribution pattern was also different in the NSW treatment compared to the other three water regimes. With this treatment, almost half of the total root length density was distributed at the lower soil depth. Drastic reduction in root growth was observed under the CF treatments compared to the IF-V at 20 DAF at both soil depths (Table 3).

Root growth and yield parameters are closely related to, i.e., responsive to, soil nutrient status, especially to soil nitrogen. Soil nitrogen status was observed to have an effect on grain formation and biomass production during the plant's reproductive growth phase. At flowering, no significant difference was found in total soil nitrogen content among IF-V, NSW and CF treatments, whereas N 
content was found to be lower in the IF-R treatment.

This could be due to the higher number of repeated drainage cycles in the IF-R compared to the IF-V treatment with resulting loss of soil $\mathrm{N}$. The ratio of ammonium $v s$. nitrate was $1: 1$ in the IF-V and IF-R treatments, whereas with CF and NSW, the ratio favoured ammonium and nitrate, respectively (Table 4). A higher nitrogen uptake was recorded in relation to dry matter production in the NSW treatment followed by IF-R, whereas nitrogen uptake was found to be lower in relation to dry matter in the CF and IF-V compared to the NSW and IF-R treatments.

$\mathrm{T}$ a $\mathrm{b} 1$ e 2

Effects of intermittent irrigation (IF-V - draining three times; IF-R - draining five times), no standing water on the soil surface (NSW) and continuously flooded (CF) water regimes on yield-contributing parameters of rice grown in pots under semi-field conditions

\begin{tabular}{|l|r|r|r|r|c|}
\hline \multirow{2}{*}{ Yield-contributing parameters } & \multicolumn{5}{|c|}{ Water regimes } \\
\cline { 2 - 6 } & $\begin{array}{c}\text { Intermittent } \\
\text { draining, 3 times } \\
\text { (IF-V) }\end{array}$ & $\begin{array}{c}\text { Intermittent } \\
\text { draining, 5 times } \\
\text { (IF-R) }\end{array}$ & $\begin{array}{c}\text { No standing } \\
\text { water (NSW) }\end{array}$ & $\begin{array}{c}\text { Continuously } \\
\text { flooded } \\
\text { (CF) }\end{array}$ & $\begin{array}{c}\text { F value } \\
(d f=3,31)\end{array}$ \\
\hline Productive tillers/plant & $47.87 \pm 0.69^{\mathrm{a}}$ & $41.75 \pm 1.32^{\mathrm{b}}$ & $38.75 \pm 0.52^{\mathrm{c}}$ & $38.88 \pm 0.89^{\mathrm{c}}$ & $51.49^{++}$ \\
Plant height [cm] & $101.35 \pm 1.17^{\mathrm{b}}$ & $103.25 \pm 1.12^{\mathrm{b}}$ & $97.12 \pm 1.24^{\mathrm{c}}$ & $107.25 \pm 0.95^{\mathrm{a}}$ & $13.46^{++}$ \\
Days to physiological maturity & $108.25 \pm 0.49^{\mathrm{b}}$ & $104.13 \pm 0.44^{\mathrm{c}}$ & $107.87 \pm 0.29^{\mathrm{a}}$ & $102.62 \pm 0.26^{\mathrm{d}}$ & $52.22^{++}$ \\
Days to 50\% flowering & $78.13 \pm 0.74^{\mathrm{c}}$ & $78.25 \pm 0.92^{\mathrm{c}}$ & $85.25 \pm 0.62^{\mathrm{a}}$ & $80.88 \pm 0.23^{\mathrm{b}}$ & $21.84^{++}$ \\
Panicle length [cm] & $32.67 \pm 0.39^{\mathrm{a}}$ & $31.69 \pm 0.79^{\mathrm{b}}$ & $30.70 \pm 0.34^{\mathrm{b}}$ & $33.08 \pm 0.34^{\mathrm{a}}$ & $4.49^{+}$ \\
Spikelets/panicle & $225.75 \pm 1.03^{\mathrm{b}}$ & $187.21 \pm 0.74^{\mathrm{b}}$ & $190.13 \pm 1.79^{\mathrm{b}}$ & $239.12 \pm 2.30^{\mathrm{a}}$ & $263.75^{++}$ \\
Sterile spikelets [\%] & $7.64 \pm 0.55^{\mathrm{b}}$ & $11.62 \pm 0.59^{\mathrm{c}}$ & $5.98 \pm 0.49^{\mathrm{a}}$ & $20.94 \pm 1.58^{\mathrm{d}}$ & $53.71^{++}$ \\
Weight of single grain [mg] & $25.25 \pm 0.19^{\mathrm{a}}$ & $23.56 \pm 0.33^{\mathrm{b}}$ & $25.58 \pm 0.27^{\mathrm{a}}$ & $23.03 \pm 0.28^{\mathrm{b}}$ & $20.72^{++}$ \\
\hline
\end{tabular}

Means ( \pm SE) followed by same letter are not significantly different at $P<0.05(\mathrm{n}=4)$

$\mathrm{T}$ a

Root length density (RLD) $\left(\mathrm{cm} / \mathrm{cm}^{3}\right)$ at flowering and 20 days after flowering of rice plant grown in pots under different water regimes (IF-V, IF-R, NSW and CF)

\begin{tabular}{|l|c|c|c|c|c|}
\hline \multirow{2}{*}{\begin{tabular}{c}
\multicolumn{1}{|c|}{$\begin{array}{c}\text { Root parameters } \\
\text { Root length density (RLD) cm/cm }\end{array}$} \\
\cline { 2 - 6 }
\end{tabular}} & $\begin{array}{c}\text { Intermittent } \\
\text { draining, } \\
\text { 3 times } \\
\text { (IF-V) }\end{array}$ & $\begin{array}{c}\text { Intermittent } \\
\text { draining, } \\
\text { times } \\
\text { (IF-R) }\end{array}$ & $\begin{array}{c}\text { No standing } \\
\text { water (NSW) }\end{array}$ & $\begin{array}{c}\text { Continuously } \\
\text { flooded (CF) }\end{array}$ & $\begin{array}{c}\text { F value } \\
(d f=3,31)\end{array}$ \\
\hline RLD at flowering (15-20 cm soil depth) & $44.43 \pm 0.62^{\mathrm{a}}$ & $42.53 \pm 0.79^{\mathrm{a}}$ & $22.78 \pm 0.68^{\mathrm{b}}$ & $44.48 \pm 0.78^{\mathrm{a}}$ & $210.87^{++}$ \\
RLD at flowering (35-40 cm soil depth & $16.05 \pm 0.41^{\mathrm{b}}$ & $13.15 \pm 0.45^{\mathrm{c}}$ & $21.66 \pm 0.71^{\mathrm{a}}$ & $10.90 \pm 0.57^{\mathrm{d}}$ & $71.14^{++}$ \\
$\begin{array}{l}\text { RLD at 20 days after flowering (15-20 cm } \\
\text { soil depth) }\end{array}$ & $27.51 \pm 0.53^{\mathrm{a}}$ & $18.99 \pm 0.73^{\mathrm{b}}$ & $14.07 \pm 0.85^{\mathrm{c}}$ & $13.76 \pm 0.60^{\mathrm{c}}$ & $85.40^{++}$ \\
$\begin{array}{l}\text { RLD at 20 days after flowering (35-40 cm } \\
\text { soil depth) }\end{array}$ & $8.88 \pm 0.45^{\mathrm{b}}$ & $7.80 \pm 0.31^{\mathrm{b}}$ & $11.54 \pm 0.33^{\mathrm{a}}$ & $5.46 \pm 0.27^{\mathrm{c}}$ & $51.35^{++}$ \\
\hline
\end{tabular}

Means $( \pm$ SE) followed by same letter are not significantly different at $P<0.05(\mathrm{n}=4)$ 


\section{c) Chlorophyll content and root activity}

After flowering, the rate of decrease in leaf chlorophyll content was recorded as higher in the $\mathrm{CF}$ and IF-R treatments compared to the IF-V and NSW treatments. The delayed senescence of the flag leaf was observed in the IF-V compared to both the IF-R and $\mathrm{CF}$ treatments. Rice grown under the NSW treatment recorded higher chlorophyll content in both leaves (upper and lower leaf) even at the later growth stage, whereas in rice under IF-V, only the flag leaves were found to remain green (Figure 3).

Higher root-oxidizing activity was observed in the $\mathrm{CF}$ and IF-V treatments at flowering, whereas at 20 DAF, a higher root-oxidizing activity was recorded only in the IF-V and NSW treatments. Root-oxidizing activity decreased significantly under CF and also in the IF-R treatments (Table 5).

\section{DISCUSSION}

A deep root system is a prerequisite for maintaining more water uptake from the soil and for better performance under drought conditions. Such performance is likely to become more important with expected climate change. A deep and healthy root system not only correlates with better water uptake but also influences yield physiology by regulating rhizosphere processes.
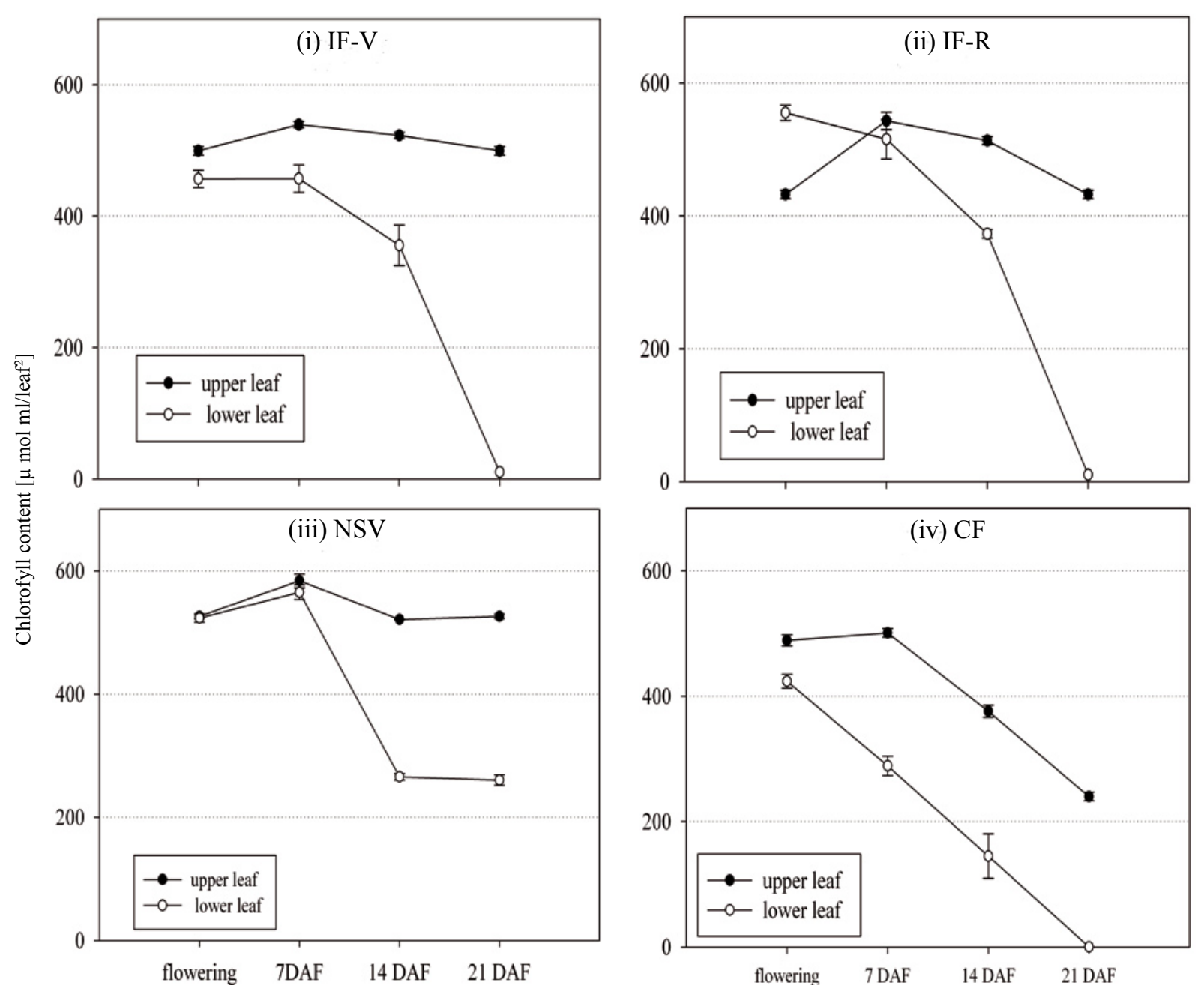

Figure 3. Changes in chlorophyll content of upper (flag leaf) and lower ( $3^{\text {rd }}$ leaf) leaf of rice plant during reproductive phase maintained under four water regimes: IF-V (intermittent draining 3 times), IF-R (intermittent draining 5 times), NSW (no standing water) and CF (continuously flooded). DAF is days after flowering. Vertical bar represents the standard error $(n=4)$. For each replicate, three leaves were used for measurement 
Among all the root parameters, root length density is the most important variable for characterizing temporal trends in the water uptake relationships of rice, especially under water-scarce conditions. The amount of water available to the plant depends on a combination of relative root-length density and the root's ability to absorb water from the soil. When root growth is better at both upper and lower soil depths, an osmotic adjustment in the early growth stage is possible, helping plants to maintain photosynthesis with an increased rate of water use efficiency (WUE).
In the present study, no significant differences in root growth and distribution were recorded between IF-V and CF conditions, but at later growth stages, higher root-length density was recorded under IF-V condition compared to the CF. The rate of root respiration activity was also higher in the IF-V, delaying the senescence of flag leaves and increasing the active grain-filling period (Table 5). This could be a key reason for higher yield in the IF-V treatments compared to any other treatments. These differences appeared only at the later reproductive stage, however, where root ag-

$\mathrm{T}$ a $\mathrm{b} 1$ e 4

Nitrogen content $\left(\mathrm{NH}_{4}^{+}+\mathrm{NO}_{3}^{-}\right)-\mathrm{N}[\mathrm{ppm}]$ of soil and plants under different water regimes (IF-V, IF-R, NSW and CF) at flowering $(\mathrm{F})$ and $20 \mathrm{DAF}$

\begin{tabular}{|l|c|c|c|}
\hline \multicolumn{1}{|c|}{ Water regimes } & Flowering (F) & 20 days after flowering (DAF) & $\begin{array}{c}\text { Nitrogen uptake by rice plant } \\
\text { (percentage of dry matter) }\end{array}$ \\
\hline $\begin{array}{l}\text { Intermittent draining, } \\
3 \text { times (IF-V) }\end{array}$ & $113.50 \pm 2.11^{\mathrm{a}}$ & $44.52 \pm 0.53^{\mathrm{a}}$ & 1.60 \\
$\begin{array}{l}\text { Intermittent draining, } \\
5 \text { times) (IF-R) }\end{array}$ & $82.53 \pm 2.09^{\mathrm{b}}$ & $11.21 \pm 1.21^{\mathrm{c}}$ & 2.21 \\
No standing water (NSW) & $113.23 \pm 2.43^{\mathrm{a}}$ & $33.12 \pm 1.39^{\mathrm{b}}$ & 1.51 \\
\hline
\end{tabular}

Means $( \pm \mathrm{SE})$ followed by same letter are not significantly different at $P<0.05(\mathrm{n}=4)$

\section{$\mathrm{T}$ a b 1 e 5}

Changes in the root-oxidizing activity (ROA), plant biomass and grain weight under varying water regimes (IF-V - intermittent draining 3 times, IF-R - intermittent draining 5 times, NSW - no standing water, and CF - continuous flooding)

\begin{tabular}{|c|c|c|c|c|}
\hline Treatment & $\begin{array}{c}\text { Root-oxidizing activity } \\
{[\mu \mathrm{g} / \mathrm{g} \text { FW/h] }} \\
\text { at flowering }\end{array}$ & $\begin{array}{c}\text { Root-oxidizing } \\
\text { activity } \\
{[\mu \mathrm{g} / \mathrm{g} \text { FW/h] at 20 days }} \\
\text { after flowering }\end{array}$ & $\begin{array}{c}\text { Total biomass } \\
{[\mathrm{g} / \mathrm{plant}]}\end{array}$ & $\begin{array}{c}\text { Dry grain weight } \\
\text { per pot }[\mathrm{g}]\end{array}$ \\
\hline $\begin{array}{c}\text { Intermittent draining } \\
3 \text { times (IF-V) } \\
\text { Intermittent draining } \\
5 \text { times (IF-R) }\end{array}$ & $63.47 \pm 0.46^{\mathrm{a}}$ & $42.28 \pm 0.90^{\mathrm{a}}$ & $341.42 \pm 6.21^{\mathrm{a}}$ & $160.77 \pm 4.02^{\mathrm{a}}$ \\
$\begin{array}{c}\text { No standing water (NSW) } \\
\text { Continuously flooded } \\
\text { (CF) }\end{array}$ & $53.14 \pm 0.49^{\mathrm{a}}$ & $32.10 \pm 0.55^{\mathrm{b}}$ & $215.84 \pm 6.06^{\mathrm{d}}$ & $103.84 \pm 4.97^{\mathrm{d}}$ \\
& $62.87 \pm 0.66^{\mathrm{b}}$ & $41.45 \pm 0.52^{\mathrm{a}}$ & $248.30 \pm 5.14^{\mathrm{c}}$ & $115.75 \pm 3.18^{\mathrm{c}}$ \\
\hline
\end{tabular}

Means $( \pm$ SE) with similar letters are not significantly different at $P<0.05(\mathrm{n}=4)$ 
ing was faster in the plants grown under CF conditions compared to the ones under IF-V.

The reason for accelerated root aging under $\mathrm{CF}$ conditions could be due to the prolonged deposition of iron oxide on the root's surface, facilitated by continuous flooding. This condition would result in restricted nutrient uptake from the soil and in limited oxygen release from the roots. Accordingly, higher accumulation of several toxic substances around the roots could result in faster senescence of roots and shoots.

In the non-flooded water regimes, a significant proportion of roots was concentrated at lower soil depths and thus there was a greater vertical distribution compared to other tested treatments. This indicates that rooting depth is more influenced by water table depth rather than by the water regime.

It was also observed that the senescence of flag leaves was delayed under IF-V conditions compared to the $\mathrm{CF}$ and IF-R conditions. The delayed senescence of flag leaves under IF-V condition was associated with higher biomass production along with higher grain weight. It was suggested by Soejima et al. (1995) that cytokinins, transported from roots to shoots, affect leaf senescence in rice during ripening phase along with maintaining higher root activity. This could be the reason that higher root activity in the IF-V prolonged the transport of cytokinins at later growth stages for delaying leaf senescence. Therefore, it can be inferred that soil nitrogen was not a limiting factor under continuously flooded conditions but rather, due to lower root activity, rice roots were unable to supply cytokinins at a later growth stage, and thus plants grown under these conditions had inferior yield performance compared to the IF-V.

In IF-R, a greater number of drainage cycles resulted in an increased rate of nitrogen loss from the soil, and this speeds up senescence. Under NSW conditions, the plant growth rate was slower compared to other water regimes, since in this treatment, $\mathrm{N}$ was mainly present in nitrate form and mainly at lower soil depths. Also, soil $\mathrm{pH}$ remains acidic at upper soil depth. This would have hindered the nutrient uptake from the soil under NSW compared to $\mathrm{CF}$ and IF-V conditions, especially in initial growth stages. However, at a later stage, the plants grown under NSW condition had better growth and yield performance compared to IF-R. This further indicates that the greater loss of soil $\mathrm{N}$ was the main reason for the poor yield performance in the IF-R condition.

Based on the above discussion, it appears that intermittent irrigation through the vegetative phase and then flooding during the reproductive phase could be an appropriate water regime for better root and shoot growth of rice in heavy clay acid-sulphate soil, compared to continuously flooded soil. This study also underscored the modular nature of root systems, which makes them amenable to both morphological and physiological plasticity when encountering a heterogeneous environment. Such malleability was seen as linked to a shoot response, and to consequent plants' dry matter production.

A range of testing is warranted under both semifield and field conditions to gain a better understanding of how plant's potential for phenotypic plasticity can be better utilized for higher crop productivity in the context of impending water constraints and crises.

\section{Implications for understanding plants' response to a dynamic soil environment}

Climate change is altering the growing environments for plants, particularly above-ground, but there are also below-ground effects as changes in precipitation and in ambient temperature have a strong influence on soil conditions. Plant species are genetically programmed to adjust to these novel conditions through phenotypic plasticity. For any given plant species, determining what responses to environmental changes can be expected will require an understanding of environmentally induced variations in the phenotypes of individual plants. Understanding of the mechanisms of plasticity will be crucial for predicting changes in crop productivity under altered environments. Therefore, it is important to identify which traits are likely to show the largest and most desirable morphological and physiological responses to particular changing environmental conditions and to understand how these can be strengthened or countervailed.

In particular, with water management strategies for irrigated rice production changing in response to the spreading physical and economical scarcity of water, understanding these responses is crucial for making optimizing adjustments in crop management so as to avoid potential yield losses. Our research suggests that positive responses can be induced through appropriate water management practices that can increase the 
total root and shoot growth and plant biomass. It also suggests that the roots and shoots are not necessarily in a zero-sum relationship, as posited by harvest index thinking; with appropriate agronomy, there can be positive feedbacks between each, as evident from this study.

While there is need to continue research to identify and/or induce more productive genotypes in general, concern for dealing with climate change should prompt more research particularly on how best to modify crop management to take advantage of plant's inherent plasticity of morphological and physiological response to environmental influences that would otherwise be limiting factors and constraints.

\section{CONCLUSION}

The above results and discussion document that rice root morphology and physiology and consequently rice shoot growth are significantly affected by variations in soil water conditions. Root's oxidizing activity rate - one of the important factors influencing higher yield in hybrid and other improved genotypes - is quite plastic in nature and varies considerably with varying water regimes. Modifying water management to take advantage of plants' inherent plasticity of morphological and physiological response can be one of the adaptive strategies for achieving higher yield under reduced water condition.

Acknowledgements. The author wishes to thank reviewers for reviewing the draft of this manuscript and offering useful comments. This research was supported in part by a grant from the Asia Rice Foundation, USA, 2005.

\section{REFERENCES}

CEESAY, M. - REID, W.S. - FERNANDES, E.C.M. - UPHOFF, N 2006. The effect of repeated soil wetting and drying on low land rice yield with System of Rice Intensification (SRI) methods. In International Journal of Agricultural Sustainability, vol. 4, 2006, no. 1, pp. 5-14. DOI:10.1080/14735903.2006.9686007

GALLARDO, M. - TURNER, N.C. - LUDWIG, C. 1994. Water relations, gas exchange and abscisic acid content of Lupinus cosentinii leaves in response to drying different proportion of the root system. In Journal of Experimental Botany, vol. 45, 1994, no. 7, pp. 909-918. DOI:10.1093/jxb/45.7.909
GEWIN, V. 2010. An underground revolution. In Nature, vol. 466 , 2010, pp. 552-553.

KAR, S. - VARADE. S.B. - SUBRAMANYAM, T.K. - GHILDAYAL, B.P. 1974. Nature and growth pattern of rice root system under submerged and unsaturated condition. In IL Riso (Italy), vol. 23, 1974, pp. 173-179.

MARKWELL, J. - OSTERMAN, J.C. - MITCHELL, J.L. 1995 Calibration of the Minolta SPAD-502 leaf chlorophyll meter. In Photosynthetic Research, vol. 46, 1995, no. 4, pp. 467-472.

McCAULEY, G.N. 1990. Sprinkler vs. flood irrigation in traditional rice production regions of southeast Texas. In Agronomy Journal, vol. 82, 1990, pp. 677-683. DOI:10.2134/agronj1990.0002 $1962008200040006 x$

MISHRA, A. - WHITTEN, M. - KETELAAR, J.W. - SALOKHE, V.M. 2006. The system of rice intensification (SRI): A challenge for science, and an opportunity for farmer empowerment towards sustainable agriculture. In International Journal of Agricultural Sustainability, vol. 4, 2006, no. 3, pp. 193-212. DOI:10.1080/14735903.2006.9684802

MISHRA, H.S. - RATHORE, T.R. - PANT, R.C. 1997. Root growth, water potential and yield of irrigated rice. In Irrigation Science, vol. 17, 1997, no. 2, pp. 69-75.

NEWELL, R.L. - WILHELM, W.W. 1987. Conservation tillage and irrigation effects on corn root development. In Agronomy Journal, vol. 79, 1987, pp. 160-165. DOI:10.2134/agronj1987.0002 $1962007900010033 \mathrm{x}$

OSAKI, M. - SHINANO, T. - MATSUMOTO, M. - ZHENG, T. - TADANO, T. 1997. A root-shoot interaction hypothesis for high productivity of field crops. In Soil Science \& Plant Nutrition, vol. 43, 1997, pp. 1079-1084.

PROFFITT, A.P.B. - BERLINER, P.R. - OOSTERHUIS, D.M. 1985. A comparative study of root distribution and water extraction efficiency by wheat grown under high and low frequency irrigation. In Agronomy Journal, vol. 77, 1985, no. 5, pp. 655-662. DOI:10.2134/agronj1985.00021962007700050001x

SAH, R.N. - MIKKELSEN, D.S. 1983. Availability and utilization of fertilizer nitrogen by rice under alternate flooding. In Plant and Soil, vol. 75, 1983, no. 2, pp. 221-226.

SATO, S. - UPHOFF, N. 2007. A review of on-farm evaluation of system of rice intensification (SRI) methods in eastern Indonesia. In CAB Review: Perspectives in Agriculture, Veterinary Science, Nutrition and Natural Resources, vol. 2, 2007, pp. 1-12.

SKINNER, R.H. - HANASON, J.D. - BENJAMIN, J.G. 1998. Root distribution following spatial separation of water and nitrogen supply in furrow irrigated corn. In Plant and Soil, vol. 199, 1998, pp. 187-194.

SOEJIMA, H. - SUGIYAMA, T. - ISHIHARA, K. 1995. Changes in the chlorophyll contents of leaves and in levels of cytokinins in root exudates during ripening of rice cultivars Nipponbare and Akenohoshi. In Plant Cell Physiology, vol. 36, 1995, pp. 1105-1114.

YANG, J. - ZHANG, J. - WANG, Z. - LIU, L. - ZHU, O. 2003. Post-anthesis water deficit enhance grain filling in two-line hybrid rice. In Crop Science, vol. 43, 2003, no. 6, pp. 2099-2108. DOI: 10.2135/cropsci2003.2099

ZHANG, X. - TAN, G. - HUANG, Y. 1994. Experimental Technology of Plant Physiology. Shenyang, China : Liaoning Science and Technology Press, 1994, pp. 51-75.

Received: August $30^{\text {th }}, 2012$ 